1 NOTICE: this is the author's version of a work that was accepted for 2 publication in Biololgical Psychology. Changes resulting from the publishing 3 process, such as peer review, editing, corrections, structural formatting, and 4 other quality control mechanisms may not be reflected in this document. 5 Changes may have been made to this work since it was submitted for 6 publication. A definitive version was subsequently published in Biological 7 Psychology, 126, doi: 10.1016/j.biopsycho.2017.04.007

\title{
Task-optimal auditory attention set restored as fast in older as in younger
}

\section{adults after distraction}

11

12

13

14

15

16

17

18

19

20

21

22

23

24

25

26

27

28

29

30

31

32

33

34

35

36

Authors:

Márta Volosin $\mathrm{a}$, b

Zsófia Anna Gaál ${ }^{\mathrm{a}}$

János Horváth ${ }^{\mathrm{a}}$

${ }^{a}$ Institute of Cognitive Neuroscience and Psychology, Research Centre for Natural Sciences,

Hungarian Academy of Sciences.

Hungary, H-1117 Budapest, Magyar Tudósok körútja 2.

${ }^{\mathrm{b}}$ Eötvös Loránd University, Faculty of Education and Psychology.

Hungary, H-1075 Budapest, Kazinczy utca 23-27.

E-mail address:

Márta Volosin: volosin.marta@ttk.mta.hu

Zsófia Anna Gaál: gaal.zsofia.anna@ttk.mta.hu

János Horváth: horvath.janos@ttk.mta.hu

Corresponding author:

Name: Márta Volosin

Phone number: +3613866819

E-mail address: volosin.marta@ttk.mta.hu

Postal address: Hungary, 1117 Budapest, Magyar Tudósok körútja 2.

Permanent address: ${ }^{a}$ Hungary, 1117 Budapest, Magyar Tudósok körútja 2.

35 pages (including 7 figures and 1 table) 


\section{Abstract}

2 The present study investigated how fast younger and older adults recovered from a distracted 3 attentional state induced by rare, unpredictable sound events. The attentional state was 4 characterized by the auditory N1 event-related potential (ERP), which is enhanced for sound 5 events in the focus of attention. Younger (19-26 years) and older (62-74 years) adults listened to

6 continuous tones containing rare pitch changes (glides) and short gaps. Glides and gaps could be 7 separated in $150 \mathrm{~ms}, 250 \mathrm{~ms}, 650 \mathrm{~ms}$ or longer and the task was gaps detection while ignoring 8 glides. With longer glide-gap separations similar N1 enhancements were observable in both 9 groups suggesting that the duration of the distracted sensory state was not affected by aging. 10 Older adults responded, however, slower at short glide-gap separations which indicated that 11 distraction at subsequent levels of processing may have nonetheless more impact in older than in 12 younger adults.

13

14 Keywords: attention, distraction, aging, N1 
Aging is associated with deteriorated frontal lobe functions which result in a decreased

3 ability to inhibit the processing of irrelevant information (Guerreiro, Murphy \& Van Gerven, 4 2010; Hasher, Lustig \& Zacks, 2007; Zanto \& Gazzeley, 2014). This leads to greater 5 susceptibility to distraction, that is, an inability to filter out task-irrelevant aspects of stimulation 6 (Chao \& Knight, 1997; Lustig, Hasher \& Zacks, 2007; Mager et al., 2005). Numerous studies 7 demonstrated that the impact of distracters on task-performance was stronger in older than in 8 younger adults (e.g. Berti, Grunwald \& Schröger, 2013; Carlson, Hasher, Connelly \& Zacks, 9 1995; Woods, 1992). Distraction, however, is not a unitary phenomenon, and ageing may affect 10 some distraction-related processes while sparing others, which might be reliably delineated by 11 method of event-related potentials (ERPs). Differences in distraction-related processes can be 12 reflected by amplitude- or latency-differences in specific ERP components (Escera \& Corral, 13 2003; Horváth, Winkler \& Bendixen, 2008). For example, Chao and Knight (1997) suggested 14 that the age-related enhancement of the Pa mid-latency auditory ERP reflected decreased 15 inhibition of incoming stimulation. Moreover, based on P3a latency differences, Horváth, 16 Czigler, Birkás, Winkler and Gervai (2009) suggested that involuntary attention switching took 17 longer in older than in the younger adults. The goal of the present study was to investigate how fast younger and older adults could restore the task-optimal attention set after distraction occurred. We utilized a recently developed, continuous stimulation distraction paradigm (Horváth \& Winkler, 2010; Horváth, 2014a), which relies on the attentional modulation of the auditory N1 ERP.

In most studies investigating the effect of aging on distraction and its electrophysiological correlates, involuntary attention switching was induced by rare (oddball) stimuli which broke the regularity of a sequence comprising frequent stimuli. Distraction was characterized by rareminus-frequent (behavioral or ERP) response differences. Studies comparing distraction effects between younger and older adults showed either no significant differences or differences with the same sign. Specifically, behavioral distraction effects (e.g. rare-minus-frequent reaction time differences) were mostly comparable between younger and older adults (Amenedo \& Diaz, 1998; Gaeta, Friedman, Ritter \& Cheng, 1998; Getzman, Gajewski \& Falkenstein, 2013; Horváth et al, 2009; Iragui, Kutas, Mitchiner \& Hillyard, 1993; Leiva, Parmentier \& Andrés, 2014; Mager et 
al., 2005), or, in some cases, older adults were more impacted by distracters (i. e. larger reaction time increase to rare stimuli, see Berti, Grunwald and Schröger, 2013; Woods, 1992).

The ERPs observable in the rare-minus-frequent difference waveform are generally interpreted as reflections of distraction-related processes: Sensory change- and deviance detection is thought to be reflected by the mismatch negativity (MMN, Näätänen, 1982), and the enhancement of the $\mathrm{N} 1$; the involuntary change in attentional orientation (distraction) is reflected by the P3a (Friedman, Cycowicz \& Gaeta, 2001; Polich, 2007). Most studies found that in older adults the ERP amplitudes were smaller (MMN: Getzman, Gajewski \& Falkenstein, 2013; Horváth et al., 2009; P3a: Gaeta et al., 1998; Iragui et al., 1993), or similar to those recorded in younger adults (MMN: Amenedo \& Diaz, 1998; Berti, Grunwald \& Schröger, 2013; Gaeta et al., 1998; Mager et al., 2005; P3a: Berti, Grunwald \& Schröger, 2013; Getzman, Gajewski \& Falkenstein, 2013; Mager et al., 2005). Similarly, the distraction-related ERPs were delayed (P3a: Gaeta et al., 1998; Getzman, Gajewski \& Falkenstein, 2013; Horváth et al., 2009; Mager et al., 2005) or were elicited with similar latency as in younger adults (MMN: Amenedo \& Diaz, 1998; Gaeta et al., 1998; Getzman, Gajewski \& Falkenstein, 2013; Horváth et al., 2009; Mager et al., 2005).

In the present study, we utilized a different approach to measure the effects of distraction (Horváth \& Winkler, 2010). Instead of interpreting the ERPs observable in the rare-minusfrequent difference waveforms, the present study exploited the well-known attentional modulation of the auditory $\mathrm{N} 1$ waveform to measure the time of recovery from distraction. In the following, we first briefly summarize the literature on the effects of attention on the N1. Then an overview of the studies suggesting that $\mathrm{N} 1$ might be a suitable tool to measure the recovery time from a distracted state is presented. Finally, we discuss these phenomena in the context of aging.

N1 is associated with the detection of change in auditory stimulation (Näätänen \& Picton, 1987). Numerous studies found that N1 was enhanced when the eliciting auditory event was in the focus of attention or the attention set was optimal to perform the task (Hansen \& Hillyard, 1980; Hillyard, Hink, Schwent \& Picton, 1973; Lange, 2013; Okamoto, Stracke, Wolters, Schmael \& Pantev, 2007). In contrast, attentional disruptions led to reduced N1 amplitudes (Horváth \& Winkler, 2010; Horváth, 2014a, 2014b). The attentional enhancements might not only reflect a genuine N1 modulation, but also the emergence of other ERP components (Woods 
\& Clayworth, 1987), like the negative difference (Nd: Hansen \& Hillyard, 1980) or processing negativity (PN: Alho, Paavilainen, Reinikainen, Sams \& Näätänen, 1986; Alho, 1992; Näätänen,

3 1982), which may overlap with the N1 (Näätänen, 1982; Woods \& Clayworth, 1987). However,

$4 \quad \mathrm{Nd}$ and PN can be separated from the N1, because in contrast to the N1, they do not show a

5 polarity inversion at the mastoids when the EEG is recorded with a nose reference (Alho et al.,

6 1986). While the enhancement of $\mathrm{N} 1$ is considered to reflect enhanced auditory event and feature

7 detection (Näätänen \& Winkler, 1999), Nd and PN are regarded as correlates of voluntary, task-

8 relevant processes, possibly indicating template-matching to the attentional trace (Alho, 1992;

9 Näätänen, 1982), and related to sustained attention (Jemel, Oades, Oknina, Achenbach \& Röpcke, 2003).

That the modulation of the N1 amplitude could be used to measure the recovery time from a distracted state is supported by several studies. First, Schröger (1996) found that when tone pairs were presented to participants, response accuracy to the second tone was reduced when it was preceded by a distracter in $200 \mathrm{~ms}$ (in comparison to those preceded by a distracter in 560 $\mathrm{ms}$ ). The performance decrease was accompanied by a positive shift in the ERP at around $100 \mathrm{~ms}$ following the tone onset. Because the positive shift also followed the distracter by about $300 \mathrm{~ms}$, it could not be, however, decided whether it reflected an attenuation of the target-related N1, or the distracter-related P3a. Studies using the continuous stimulation paradigm introduced by Horváth and Winkler (2010) showed that task-relevant auditory events indeed elicited lower amplitude N1s when shortly preceded by distracter events. In this paradigm, continuous tones are presented, which alternate between two pitches by rare, short glissandos (glides). The participants' task is to detect and respond to frequently occurring short silent periods (gaps) while ignoring the glides. It was found that a 150 ms glide-gap separation resulted in reduced gaprelated N1s and lower gap detection rates in comparison to gaps not preceded by other events in at least $1300 \mathrm{~ms}$. In a later study using the continuous stimulation paradigm Horváth (2014a) found that the distraction effects (N1 amplitude and detection rate reductions) did not last longer than $650 \mathrm{~ms}$. These results fit well into the literature of the auditory attentional blink (see for example, Shen \& Mondor, 2006; Tremblay, Vachon \& Jones, 2005). In most attentional blink paradigms, two target stimuli are embedded in a rapid tone-sequence, and detection of the second 
the second target elicited lower-amplitude N1 when it was immediately preceded by the first target, in comparison to the case when the targets were separated by six intervening tones.

N1 elicitation also differs between age groups. For N1s elicited by tone onsets, N1 amplitude was mostly found to be higher in older adults (Anderer, Semlitsch \& Saletu, 1996; Amenedo \& Diaz, 1998; Chao \& Knight, 1997), or no age-related differences were observed (Getzman, Gajewski \& Falkenstein, 2013; Horváth et al., 2009; Mager et al., 2005; Pfefferbaum,

7 Ford, Roth \& Koppel, 1980; Woods, 1992; but see also Berti, Grunwald \& Schröger, 2013). In contrast, gaps in continuous tones seem to elicit lower amplitude N1s in older than in younger adults (Alain, McDonald, Ostroff \& Schneider, 2004; Harris, Wilson, Eckert \& Dubno, 2012).

Experimental data on the duration of the distracted state induced by rare auditory events, and its dependence on age is scarce. Slawinski and Goddard (2001) presented short sinusoidal tones in a rapid auditory stream, and participants had to identify the pitch (low, medium, high) of the tone with higher sound pressure than the others. When only the probe stimulus was presented with higher sound pressure, both groups completed the task adequately, although the younger adult group slightly outperformed older adults. When both probe and targets were salient, the performance of older adults was significantly reduced compared to the younger adult group in general, and older adults showed an impaired performance in time intervals from 90 to $450 \mathrm{~ms}$. Both groups detected probes poorly from 90 to $360 \mathrm{~ms}$, suggesting that recovery from distraction - reflected by behavioral indices - happens by about $360 \mathrm{~ms}$ in younger adults and slightly later in the older adults.

Based on the studies summarized above, the aim of the present study was to compare the duration of the distracted sensory state induced by task-irrelevant, rare stimuli between older and younger adults, as reflected by the modulation of the N1 ERP. We administered the continuous stimulation paradigm introduced by Horváth and Winkler (2010) with minor modifications. The participants' task was to listen to the continuous tone and press a button when a gap occurred, while ignoring glides. The presentation frequency of the glides (serving as task-irrelevant distracter events) was identical to the one used in the study by Horváth and Winkler (2010), that is, they could occur with $1 / 7$ probability at every $1300 \mathrm{~ms}$. Glides preceded potential gappositions by 150,250 or $650 \mathrm{~ms}$. Gaps were presented with $50 \%$ probability every $1300 \mathrm{~ms}$ at one of these time-points. Gaps not preceded by any glides in at least $1450 \mathrm{~ms}$ (gap only trials) 
1 allowed the measurement of the maximal gap-related N1 amplitude. We hypothesized that shorter

2 glide-gap separations would lead to stronger N1 amplitude reductions because the optimal 3 attention set for detecting a gap could not be fully restored after distraction occurred. We also

4 hypothesized that in older adults, the effects of distraction - manifested in lower N1 amplitudes 5 would persist longer.

\section{Methods}

\section{Participants}

52 healthy adult women participated in the experiment: 25 younger (age: from 19 to 26; mean: 22.2 years) and 27 older (age: from 62 to 75; mean: 67.5 years) adults. Because of excessive amount of eye movement artifacts (3 younger adults) or poor task performance (false alarm rates above $40 \%$ - further 1 younger, and 9 older adults, or detection rates for 150 and 250 ms gaps below $66 \%$ - resulting in low epoch numbers - another 5 younger and 2 older adults), only 32 participants remained in the final analyses. That is, our results are based on the behavioral and ERP data of 16 younger (age: from 19 to 26; mean: 22.6 years) and 16 older (age: from 62 to 74 years, mean: 67.3 years) persons. Participants were free of any neurological or psychiatric disease by their own admission. They were compensated by modest amounts of money for taking part in the experiment. The study was approved by the United Ethical Review Committee for Research in Psychology (Hungary), and all participants gave written informed consent.

All participants reported correct or corrected-to-normal vision. Only persons with hearing threshold differences not more than $20 \mathrm{~dB}$ between the two ears in the $250-2000 \mathrm{~Hz}$ range (as measured by a SA-6 audiometer, MEDIROLL, Debrecen, Hungary) participated in the experiment. Older adults had higher thresholds than younger adults at all frequencies (see Table 1). To compensate for threshold differences, the amplitude of the experimental sounds were individually adjusted to $50 \mathrm{~dB}$ above the $75 \%$ hearing threshold for the continuous tone used in the experiment (as described below), using the single interval adjustment matrix (SIAM) method

28 (Kaernbach, 1990; Shepherd, Hautus, Stocks \& Quek, 2011). The older adult group was 
variances t-test: $\mathrm{t}[29.521]=4.963, \mathrm{p}<.001)$ as assessed by the Hungarian version of the

2 Wechsler Intelligence Scale (WAIS-IV; Wechsler, 2008) administered in a separate session. The 3 total mean score was $130.8(\mathrm{SD}=14.18)$ in the older adults and 107.3 $(\mathrm{SD}=12.4)$ in the younger

4 adults group, suggesting that both groups were characterized with intelligence higher than the 5 average as shown by one-sample Student's t-tests (older adults: $\mathrm{t}[15]=8.673, \mathrm{p}<.01$; younger 6 adults: $\mathrm{t}[15]=2.344, \mathrm{p}=.03$ ).

Stimuli and procedure

Participants were sitting in a comfortable chair in a dimly lit, sound-attenuated room and listened to 4-minutes-long continuous tones through Sennheiser (HD-600, Sennheiser, 11 Wedemark, Germany) headphones. The tones were generated with Csound version 5.17.11 (www.csounds.com), with a sampling rate of $44.1 \mathrm{kHz}$. The tones consisted of three harmonics: the fundamental and the second and third harmonics (the first harmonic was missing), with equal amplitude. The base frequency was either $220 \mathrm{~Hz}$ (low) or $277 \mathrm{~Hz}$ (high), and the pitch of the tone changed occasionally from high to low, or low to high with a $10 \mathrm{~ms}$ transition time (glide). Glides could occur in the 4 minutes-long continuous tone at discrete time points separated by $1300 \mathrm{~ms}$ steps, and they occurred randomly with $14.28 \%$ probability at each time point, with the constraint that successive glides were separated by at least $3900 \mathrm{~ms}$. That is, in average, 27 glides were presented in a block. Beside glides, short gaps $(10 \mathrm{~ms}$ long silent periods preceded by a 10 ms linear fall and followed by a $10 \mathrm{~ms}$ linear rise) were also inserted in the tone. Gaps could occur at time points following the potential glide-time points within $650 \mathrm{~ms}$ with $50 \%$ probability. $35.7 \%$ of such gaps followed the potential glide time point by $150 \mathrm{~ms}, 28.6 \%$ by 250 $\mathrm{ms}$, and $35.7 \%$ by $650 \mathrm{~ms}$. Gaps following actual glides within $650 \mathrm{~ms}$, are referred to as $150 \mathrm{~ms}$, $250 \mathrm{~ms}$ and $650 \mathrm{~ms}$ gaps in the following. The rest of the gaps (i.e. those which were not preceded by a glide within $1450 \mathrm{~ms}$ ) are termed "gap only" trials. The schematic illustration of the tones including glides and gaps is presented in Fig. 1.

Participants performed a gap detection task: they were instructed to press a button held in their dominant hand when they detected a gap, while ignoring the glides. The first block was a 

on grey background. After $10 \mathrm{~s}$, the "START" text changed to a black fixation cross and the tones

3 started to play. At the end of each block, feedback about the gap detection rate (the ratio of

4 correctly detected gaps to all presented gaps) and the mean reaction time was displayed on the

5 screen. Between the blocks, short (1-2 min) pauses were available as needed, with a longer (5-10

6 min) break after the $7^{\text {th }}$ experimental block.

EEG recording

The continuous EEG was recorded with a sampling rate of $500 \mathrm{~Hz}$ (with $100 \mathrm{~Hz}$ online lowpass filtering) with a Neuroscan Synamp 2 (Compumedics Inc., Victoria, Australia) amplifier with $61 \mathrm{Ag} / \mathrm{AgCl}$ electrodes mounted on an elastic cap (EASYCAP GmbH, Herrsching, Germany) arranged according to the $10 \%$ system (Nuwer, 1998). Two additional electrodes were 13 placed at the mastoids. The reference electrode was placed on the tip of the nose and the ground electrode was attached on the forehead. Horizontal electro-oculogram was measured by electrodes attached near the outer canthi of the left and the right eye, and the vertical electrooculogram was calculated offline as the difference of the signal between the Fp1 electrode and an additional electrode placed under the left eye. The continuous EEG data was filtered offline using a $30 \mathrm{~Hz}$ lowpass filter (Kaiser-windowed sinc finite impulse response filter, beta of 5.65, 907 coefficients; $2 \mathrm{~Hz}$ transition bandwidth, stopband attenuation at least $60 \mathrm{~dB}$ ).

For an overview of the ERP epochs selected for the analyses, see Figure 2. For all the ERP analyses, glides and gaps with no keypresses in the preceding $300 \mathrm{~ms}$ were selected, as well as gaps following such glides in $150 \mathrm{~ms}, 250 \mathrm{~ms}$ or $650 \mathrm{~ms}$. "Gap only" trials were also selected: these gaps were not preceded by a glide in at least $1450 \mathrm{~ms}$ or by another gap in at least $3400 \mathrm{~ms}$, that is, no distracting events were present before them. To estimate the gap-related ERP activity without potentially overlapping glide-related ERP waveforms, timepoints were selected in which gaps could but did not occur (i. e. $150 \mathrm{~ms}, 250 \mathrm{~ms}$ and $650 \mathrm{~ms}$ after potential glide timepoints and after the onset of glides which were not followed by any events in $650 \mathrm{~ms}$ ), labeled as control gaps. $800 \mathrm{~ms}$ long epochs were extracted for each of these time-points including a $150 \mathrm{~ms}$ pretimepoint baseline. Epochs with a signal range exceeding $150 \mu \mathrm{V}$ on any channel were discarded 
1 from further processing. Average ERPs calculated from the control epochs were subtracted from

2 the corresponding gap-related $(150 \mathrm{~ms}, 250 \mathrm{~ms}, 650 \mathrm{~ms}$ and gap only) average ERPs. The

3 resulting waveforms are referred to as corrected waveforms in the following. The averaged

$4 \quad$ ERPs, control gaps and the corrected waveforms are presented in Fig 2.

Statistical analyses

Reaction times were analyzed only for detected gaps which were not preceded by any keypress in $300 \mathrm{~ms}$, separately for each glide-gap separation $(150 \mathrm{~ms}, 250 \mathrm{~ms}$ and $650 \mathrm{~ms}$ and gap only). Only responses which occurred between $120 \mathrm{~ms}$ and $1000 \mathrm{~ms}$ after the gap onset were included into analysis. Median reaction times were calculated for every participant, which were submitted to Group (younger adults / older adults) × Gap Type (150 ms / 250 ms / 650 ms / gap only) ANOVA. Detection rates were submitted to an ANOVA of the same structure. The number of false alarms was also calculated by selecting glides with no preceding events in 300 ms which were followed by a keypress in 120 to $1000 \mathrm{~ms}$. The ratio of these responses to all presented glides defined the false alarm rate which was compared between groups by Welch's t-tests.

Although our primary hypotheses were related to the modulation of $\mathrm{N} 1$ component, later waveforms (P2, N2, P3b) were elicited and modulated as well, therefore we included them into the analysis. Gap-related ERPs (N1, P2, N2, P3b) were identified in the group-average corrected waveforms for detected "gap only" trials. Individual N1, P2 and N2 amplitudes were measured as the average signal in a $20 \mathrm{~ms}$ long windows centered at the "gap only" peak latency in a frontocentral (FCz, Cz, Fz, FC1 and FC2) electrode cluster; P3b amplitudes were measured as the average signal in $100 \mathrm{~ms}$ long window centered at the "gap only" peak latency at a parietal cluster (Pz, POz, CPz, P1, P2) of electrodes to enhance signal-to-noise ratio. The "gap only" amplitudes were compared by Welch's t-tests between groups, then one-way ANOVAs were used to assess for different Gap Types (150 ms / $250 \mathrm{~ms} / 650 \mathrm{~ms} /$ gap only) separately for the two groups. Significant Gap Type effects were followed up by pairwise t-tests. To compare the glide-gap separation related modulation of the N1 amplitude between groups, the amplitudes were normalized by the gap-related N1 amplitudes measured in the corrected gap only waveforms for each group. These normalized amplitudes were submitted to Group (younger 
adults / older adults $) \times$ Gap Type $(150 \mathrm{~ms} / 250 \mathrm{~ms} / 650 \mathrm{~ms})$ ANOVAs. Glide-related N1 and

2 P2 amplitudes measured at the fronto-central cluster for glides which were not followed by any

3 gaps in $650 \mathrm{~ms}$ (glide only) were compared between younger and older adults groups using

4 Welch's t-test. All statistical tests were conducted by using R (version 3.1.0, R Core Team,

5 2014). Generalized eta squared $\left(\eta_{G}^{2}\right)$ effect sizes are also reported (Olejnik \& Algina, 2003;

6 Bakeman, 2005).

$8 \quad$ Results

9 Behavioral performance

Reaction times and gap detection rates are presented in Fig. 3. The Group $\times$ Gap Type 11 ANOVA of the reaction times showed a significant Gap Type main effect $(\mathrm{F}[3,90]=16.45, \mathrm{p}<$ $\left.12.001, \eta_{G}^{2}=.07\right)$, and a significant Group $\times$ Gap Type interaction $\left(F[3,90]=4.83, p=.004, \eta_{G}^{2}=\right.$ $13.022)$. The Group main effect was not significant $\left(\mathrm{F}[1,30]=.002, \mathrm{p}=.961, \eta_{\mathrm{G}}^{2}<.001\right)$. 14 Analyzing the two groups separately, in older adults a Gap Type main effect was found: $F(3,45)$ $15=20.07, \mathrm{p}<.001 ; \eta_{\mathrm{G}}^{2}=.11$, which was followed up by pairwise t-tests. Responses were 16 significantly slower with decreasing glide-gap separations (i.e. all but the $650 \mathrm{~ms}$ vs. gap only 17 comparison showed significant differences: t-scores $>3.238$, p-values $<.01$ ). In contrast, no significant Gap Type effect was found in the younger adults group: $\mathrm{F}(3,45)=2.67, \mathrm{p}=.06, \eta_{\mathrm{G}}^{2}=$ .04 .

The ANOVA of the gap detection rates (Fig. 3., right) showed a significant Gap Type main effect only: $\mathrm{F}(3,90)=6.946, \mathrm{p}<.001, \eta_{\mathrm{G}}^{2}=.093$, indicating that participants in both age groups detected more gaps with increasing glide-gap separation. Neither the Group main effect $\left(\mathrm{F}[1,30]=.778, \mathrm{p}=.385, \eta_{\mathrm{G}}^{2}=.014\right)$, nor the Group $\times$ Gap Type interaction effects were significant $\left(F[3,90]=.58, \mathrm{p}=.63, \eta_{\mathrm{G}}^{2}=.001\right)$.

Participants could also inadvertently respond to glides as well, not only to gaps. To assess this, we selected glide only trials (no following gaps in $650 \mathrm{~ms}$ ) and the ratio of keypresses to them in 120 to $1000 \mathrm{~ms}$ interval was calculated. The occurrence rate of such false alarms did not differ between the older and younger adults $(\mathrm{t}[21.542]=.385, \mathrm{p}=.703)$ : older adults responded 
1 in average to $11.72 \%$ of glides and younger adults in $12.74 \%$ (note that participants with higher

2 than $40 \%$ false alarm rate were omitted from the original sample).

$4 \quad$ Event-related potentials

Individual ERPs were averaged separately for the two age groups and for the four gap types (gap only, $150 \mathrm{~ms}, 250 \mathrm{~ms}, 650 \mathrm{~ms}$ ) on the corrected waveforms, as well as for glide only trials. The average number of epochs in the younger adults group was $50( \pm 12)$ for $150 \mathrm{~ms}$ gaps, $41( \pm 9)$ for $250 \mathrm{~ms}$ gaps, $51( \pm 11)$ for $650 \mathrm{~ms}$ gaps, $604( \pm 95)$ for gap only trials and $138( \pm 20)$ for glide only trials. In the older adults group, the number of epochs was $58( \pm 12)$ for $150 \mathrm{~ms}$ gaps, $44( \pm 9)$ for $250 \mathrm{~ms}$ gaps, $55( \pm 8)$ for $650 \mathrm{~ms}$ gaps, $666( \pm 96)$ for gap only trials and 150 $( \pm 20)$ for glide only trials.

On the corrected gap only waveforms, a negativity (N1) was peaking at $152 \mathrm{~ms}$ at FCz in the younger and at $160 \mathrm{~ms}$ at $\mathrm{Cz}$ electrode in the older adult group. However, the mastoid polarity inversion peaked earlier in both groups (114 $\mathrm{ms}$ in the younger and $110 \mathrm{~ms}$ in the older adults), suggesting that the fronto-central waveform included multiple components: a supra-temporal N1 and a PN (or Nd; Alho, 1986). Indeed, in the older adult group, two slightly overlapping peaks were elicited for short glide-gap separations. In the younger adults, these components might have completely overlapped, resulting in only a single observable peak. To investigate whether the supra-temporal N1 component was affected, an additional analysis was conducted in the time window of the earlier (mastoid) peak both at the fronto-central cluster and at the averaged mastoids. In the younger adults group, N1/PN was followed by a positivity (P2) peaking at 218 $\mathrm{ms}$ at $\mathrm{Cz}$ lead but this component was absent in the older adults. Although a well identifiable P2 was not present in the older adult group, a positive peak was nonetheless observable at $230 \mathrm{~ms}$ at AF8 electrode in the group-average corrected gap only ERP, therefore, in the older adult group the P2 amplitude was characterized as the average signal in the $220-240 \mathrm{~ms}$ interval. P2 was followed by a negativity (N2), peaking for gap only trials at $326 \mathrm{~ms}$ at Fz in the younger adults and at $328 \mathrm{~ms}$ at $\mathrm{C} 1$ in the old adult group. The P3b waveform for gap only trials reached its maximum amplitude at $\mathrm{Pz}$ in both groups, with $428 \mathrm{~ms}$ latency in the younger adult group, and at $504 \mathrm{~ms}$ in the older adult group. 
Glide only trials elicited a clear N1 in both groups, peaking at $130 \mathrm{~ms}$ at FCz in the younger, and at $106 \mathrm{~ms}$ at $\mathrm{Fz}$ in the older adults. The ERP amplitudes were compared between the two groups using Welch's t-test. In the younger adult group, N1 was followed by a P2 peaking at $206 \mathrm{~ms}$ at $\mathrm{Cz}$. This component was less obvious in the older adult group (the maximum amplitude peak was at AF8 at $216 \mathrm{~ms}$ ). The ERP results are plotted in Fig. 4 and the corresponding scalp topographies of the analyzed components are presented in Fig. 6 and Fig. 7.

In the later N1 time window, younger adults exhibited significantly higher (more negative) amplitudes in the corrected gap only waveforms than older adults $(\mathrm{t}[29.382]=-3.14, \mathrm{p}$ $=.004)$. Therefore, we compared the amplitudes elicited by the four Gap Types, separately for the two age groups. Significant Gap Type main effects were present both in the younger $(F[3,45]=$ 23.133, $\left.\mathrm{p}<.001, \eta_{\mathrm{G}}^{2}=.28\right)$ and the older adult group $\left(\mathrm{F}[3,45]=6.462, \mathrm{p}<.001, \eta_{\mathrm{G}}^{2}=.138\right)$. The follow-up paired t-tests revealed that in the younger adults all four amplitudes differed from each other (all $\mathrm{t}$ values > 3.218; all $\mathrm{p}$ values < .006), except for the $650 \mathrm{~ms}$ gaps and gap only trials which were similar $(\mathrm{t}[15]=.068, \mathrm{p}=.947)$. In the older adults, the $150 \mathrm{~ms}$ gaps amplitudes differed only from $650 \mathrm{~ms}(\mathrm{t}[15]=2.739, \mathrm{p}=.015)$ and from gap only trials $(\mathrm{t}[15]=3.999, \mathrm{p}=$ .001 ); and the $250 \mathrm{~ms}$ gap amplitudes were also lower than amplitudes elicited by gap only trials $(\mathrm{t}[15]=2.459, \mathrm{p}=.027)$. For the normalized amplitudes, the Group $\times$ Gap Type ANOVA showed only a significant Gap Type main effect $\left(F[2,60]=16.661, p<.001, \eta^{2}{ }_{G}=.163\right)$, indicating that $\mathrm{N} 1$ amplitudes increased with increasing glide-gap separation (Fig. 5, left). Neither the main effect of Group $\left(\mathrm{F}[1,30]=.012, \mathrm{p}=.914, \eta^{2}{ }_{\mathrm{G}}<.001\right)$, nor the Group $\times$ Gap Type interaction $\left(\mathrm{F}[2,60]=.335, \mathrm{p}=.717, \eta_{\mathrm{G}}^{2}=.004\right)$ were significant, however. For normalized amplitudes, see Fig.3.

In the earlier $\mathrm{N} 1$ time window (i.e. at the latency of the mastoid polarity inversion), amplitudes in the corrected gap only waveforms did not differ in the two groups at the frontocentral electrodes $(\mathrm{t}[29.376]=.267, \mathrm{p}=.792)$. The Group $\times$ Gap Type ANOVA for normalized amplitudes showed no significant effects (Group main effect: $F[1,30]=1.392, p=.247, \eta_{G}^{2}=$ .03 ; Gap Type main effect: $F[2,60]=3.131, \mathrm{p}=.051, \eta^{2}{ }_{\mathrm{G}}=.034$; Group $\times$ Gap Type interaction: $\left.\mathrm{F}[2,60]=1.83, \mathrm{p}=.169, \eta_{\mathrm{G}}^{2}=.02\right)$. No significant amplitude differences were found at the mastoids either (between-group amplitude differences in the corrected gap only waveforms: $\mathrm{t}[29.976]=.748, \mathrm{p}=.46$; for the Group $\times$ Gap Type ANOVA for normalized amplitudes: Group 
main effect: $F[1,30]=1.863, p=.182, \eta^{2}{ }_{G}=.026$; Gap Type main effect: $F[2,60]=1.136, p=$ $.328, \eta_{G}^{2}=.021$; Group $\times$ Gap Type interaction: $\left.F[2,60]=1.806, p=.173, \eta_{G}^{2}=.033\right)$.

Because the gap-related P2 waveform was not readily observable in older adults (see

4 Fig.6), we analyzed the amplitudes without normalizing the data in Group (younger adults / older adults) $\times$ Gap Type (150 ms / $250 \mathrm{~ms} / 650 \mathrm{~ms} /$ gap only) ANOVA. Not only the main effects of Group $\left(F[1,30]=15.922, p<.001, \eta_{G}^{2}=.259\right)$ and Gap Type $\left(F[3,90]=4.464, p=.006, \eta_{G}^{2}=\right.$ 7 .048) were significant, but the Group $\times$ Gap Type interaction as well: $F(3,90)=4.253, p=.007$, $8 \eta_{G}^{2}=.046$. Analyzing the two groups separately, while Gap Type did not affect the amplitudes 9 in the P2 time window in the older adults $\left(\mathrm{F}[3,45]=.079, \mathrm{p}=.97, \eta_{\mathrm{G}}^{2}=.002\right)$, younger adults exhibited significantly lower amplitudes as glide-gap separation interval decreased $(\mathrm{F}[3,45]=$ $\left.8.66, \mathrm{p}<.001, \eta_{\mathrm{G}}^{2}=.161\right)$. Following-up the main effect in the younger adult group, paired ttests revealed that the amplitudes of $150 \mathrm{~ms}$ gaps were significantly lower than $650 \mathrm{~ms}$ gaps $(\mathrm{t}[15]=-3.041, \mathrm{p}=.008)$ and gap only trials $(\mathrm{t}[15]=-3.096, \mathrm{p}=.007)$. The amplitudes of $250 \mathrm{~ms}$ gaps also differed from $650 \mathrm{~ms}$ gaps $(\mathrm{t}[15]=-3.346, \mathrm{p}=.004)$ and from gap only amplitudes $(\mathrm{t}[15]=-3.539, \mathrm{p}=.003)$.

Because of the obvious overlap between the N2 and P3b waveforms (Fig. 4 and Fig. 7), corrected amplitudes in the N2 time-range were submitted without normalization to a Group (younger / older adults) $\times$ Gap Type $(150 \mathrm{~ms} / 250 \mathrm{~ms} / 650 \mathrm{~ms} /$ gap only) ANOVA. The ANOVA revealed neither a significant Group main effect $\left(F[1,30]=2.326, p=.138, \eta^{2}{ }_{G}=.051\right)$, nor a Group $\times$ Gap Type interaction $\left(F[3,90]=.838, p=.477, \eta_{G}^{2}=.009\right)$. Only a significant Gap Position main effect was found: $F(3,90)=9.69, p<.001, \eta^{2}{ }_{G}=.09$, showing that glide-gap separation intervals had similar effect on $\mathrm{N} 2$ amplitudes in both groups.

The P3b in gap only trials was elicited with significantly higher amplitudes in the younger adult group than in the older adult one $(\mathrm{t}[29.211]=2.615, \mathrm{p}=.013)$. Analyzing the groups separately, the corrected amplitudes did not differ from each other in the younger adult group $\left(\mathrm{F}[3,45]=.626, \mathrm{p}=.602, \eta_{\mathrm{G}}^{2}=.014\right)$, whereas in the older adults, the Gap Type main effect was significant: $\mathrm{F}(3,45)=6.251, \mathrm{p}=.001, \eta_{\mathrm{G}}^{2}=.084$. The amplitude of gap only trials was higher than any other gap types $(150$ ms gaps: $\mathrm{t}[15]=-3.045, \mathrm{p}=.008 ; 250$ ms gaps: $\mathrm{t}[15]=-2.344, \mathrm{p}=$ $.033 ; 650$ ms gaps: $\mathrm{t}[15]=-4.402, \mathrm{p}<.001)$ and the difference between $150 \mathrm{~ms}$ gaps and $650 \mathrm{~ms}$ gaps was also significant $(\mathrm{t}[15]=2.132, \mathrm{p}=.05)$. Glide-related $\mathrm{N} 1$ and P2 amplitudes were 
1 compared between older and younger adult groups by Welch's t-test on the same fronto-central

2 cluster as in case of gap-related ERPs. For the N1 no significant difference was found (t[28.536]

$3=1.302, \mathrm{p}=.203$ ), however, $\mathrm{P} 2$ amplitude was significantly higher in the younger than in the

4 older adult group $(\mathrm{t}[29.882]=-4.224, \mathrm{p}<.001)$.

Discussion

The goal of the present study was to measure how fast younger and older adults restored task-optimal attention set after distraction occurred. To characterize the duration of the distracted

9 state, $\mathrm{N} 1$ amplitudes elicited by gaps were measured in a gap detection task in which the temporal separation between distracters (glides) and targets (gaps) was manipulated. In younger adults, gaps elicited a series of N1, P2, N2 and P3b waveforms; in older adults, however, P2 was absent. N2 and P3b overlapped partially. Gaps elicited smaller N1s in older than in younger adults; the magnitude of $\mathrm{N} 1$ reduction with decreasing glide-gap separation was, however, similar in the two groups. The lack of polarity inversion at the mastoids in the time window of the negative frontocentral N1 peak suggests that the amplitude reduction was not caused by the modulation of the auditory N1 subcomponent, rather, that it was caused by the absence of an additional negativity, presumably a PN reflecting the matching of the auditory event to a task-relevant sensory template. With shorter glide-gap separations accuracy decreased. Whereas older adults responded systematically slower as glide-gap separations got shorter, glide-gap separation did not significantly influence reaction times in younger adults. The distracter glides elicited similar N1s in both groups, but $\mathrm{P} 2$ was more pronounced in younger adults.

The lower gap-related N1 amplitudes in the older than in younger adults, are in line with previous studies (Alain et al., 2004; Harris et al., 2012); and the modulation of N1 amplitudes also fits, and extends the literature. The decreased N1 amplitudes at 150 and $250 \mathrm{~ms}$ glide-gap separation suggest that the distracted state persisted for at least $250 \mathrm{~ms}$, while the lack of difference between the N1s elicited in the gap only and the $650 \mathrm{~ms}$ glide-gap separation trials suggest that attention was restored by $650 \mathrm{~ms}$ after distraction occurred. These results are on a par with the results by Schröger (1996), Horváth (2014a) and Horváth and Winkler (2010). The topographical distribution of the N1-effect (no polarity inversion at the mastoids) and its latency 
1 (i.e. peaking later than the positive $\mathrm{N} 1$ aspect at the mastoids) also support the notion (Horváth, 2 2014a) that the modulation of the N1 waveform might be not a "genuine" modulation of the 3 auditory $\mathrm{N} 1$ subcomponent, but the modulation of the overlapping processing negativity which is

4 characteristically elicited by task-relevant auditory events (Näätänen, 1982).

In contrast to the $\mathrm{N} 1$ which was present in both groups, a readily observable $\mathrm{P} 2$ was 6 elicited only in the younger adults. In the young adults, however, it was characterized with 7 similar pattern as the N1 modulatory effect: as glide-gap separation decreased, P2 amplitude also 8 became lower. The functional role of P2 waveform is poorly understood. Recent studies show 9 that N1 and P2 are rather independent components (Crowley \& Colrain, 2004) and P2 might index processes related to detection threshold mechanisms and stimulus evaluation (Ceponiene, Alku, Westernfield, Torki \& Townsend, 2005). The P2 attenuation pattern in younger adults indicates that the distracting effect of glides also affected stimulus evaluation processes since attention was still captured by glides as demonstrated by Horváth and Winkler (2010) as well: in their study, P2 was attenuated to $150 \mathrm{~ms}$ glide-gap separation compared to the gaps presented alone. In the present study, the absence of P2 in the older adults might be explained with the superimposition of earlier negative ERPs, especially the PN: PN might overlap the P2 time interval and cancel that component as suggested by Crowley and Colrain (2004). Also, because Harris and colleagues (2012) found reduced P2 amplitudes to gaps in older adults, the age-related changes in gap detection processes also could lead to this effect.

The pattern of later ERP waveforms supports the interpretation of the N1/PN modulation presented above. When glides and gaps were presented with a longer separation (650 ms and gap only trials), an N2 was elicited. For $150 \mathrm{~ms}$ and $250 \mathrm{~ms}$ gaps this component was entirely absent in both groups. Since N2 is thought to reflect categorization and decision mechanisms (Folstein \& Van Petten, 2008; Patel \& Azzam, 2005; Ritter, Simson, Vaughan \& Macht, 1982), these results suggest that the disruption of the attentional template also affected these later, endogenous processes, irrespectively of age. The subsequent P3b waveform indexing target detection (Polich, 1997) was also modulated by the presence of distracters: both groups demonstrated amplitude decrease with decreasing glide-gap intervals. One could interpret this effect as disturbance in target identification, however, it is important to note that the $\mathrm{N} 2$ at least partly overlaps $\mathrm{P} 3 \mathrm{~b}$ in the frontal areas. This overlap might modulate P3b amplitudes which might be not identical in 
different conditions. Moreover, some studies revealed that in tasks requiring sustained attention, a further processing of attended stimuli might be present (Näätänen \& Michie, 1979), especially in

3 the older adults, also leading to P3 modulation (Karayanidis, Andrews, Ward \& Michie, 1995).

4 The present study does not allow the separation of these contributions, therefore the results on N2 and P3b should be interpreted cautiously.

In order to discuss the effects of attention on gap-related ERPs, it is important to take into consideration glide-related ERPs well. Glides elicited an N1 and a P2 in both groups but N2 and P3b were not present. The N1 and P2 pattern was similar to those observable on gap-related ERPs: while N1 was pronounced in both groups, older adults demonstrated only moderate P2. The latter could be explained with age-related P2 differences in gap processing (Harris et al., 2012) or the partial superimposition with the previous negativity (Crowley \& Colrain, 2004).

The behavioral results are in line both with the electrophysiological results and with the literature. The accuracy scores in younger and older participants were affected by different glidegap separations similarly: both groups detected gaps less accurately when glides preceded them in short time intervals, reflecting the presence of a distraction effect in general (Berti, Grunwald \& Schröger, 2013). Lower target detection rates for brief distracter-target separations were also demonstrated in discrete (Horváth \& Burgyán, 2011; Schröger, 1996) and in continuous stimulation protocols (Horváth, 2014a; Horváth \& Winkler, 2010). Our results regarding the lack of group differences in target detection rate with the change of distraction-target separation interval is at odds with the results of Slawinski and Goddard (2001), who found that while both age groups detected targets following attention capture by $360 \mathrm{~ms}$ poorly, the performance of older adults was still impaired at $450 \mathrm{~ms}$. An explanation to the difference between the two studies might be that while Slawinski and Goddard (2001) utilized discrete sinusoidal tone pips in rapid presentation, we presented continuous complex tones which led to lower task difficulty and better performance even at cognitively demanding conditions. It is also important to note that the exclusion of participants with insufficient numbers of responses to gaps could bias gap detection rate results. participants slowed gradually as glides and gaps got closer to each other. In contrast, younger adults could keep their response speed steady between the different glide-gap separations. That is, 
1 as task difficulty increased, older adults needed to invest more effort into the task while younger

2 adults could maintain their performance, in other words, older adults had to compensate with 3 enhanced attention (Reuter-Lorenz \& Cappell, 2008; Zanto \& Gazzeley, 2014). Albeit for the

4 first sight it seems that older adults are more susceptible for distraction, taken accuracy data into

5 consideration, this response pattern might suggest differences not only in cognitive abilities but in

6 task performance strategies as well. On one hand, a trade-off mechanism might be present in

7 older adults favoring high accuracy over speed (Leiva, Andrés \& Parmentier, 2015). It was

8 demonstrated that older adults tended to be more cautious than younger adults even when they

9 were instructed to respond as fast as possible, which is also related to age-related structural

10 changes in brain connectivity (Forstmann et al., 2011). On the other hand, motivational and

11 detection threshold factors could also lead to reaction time differences: while older adults seemed

12 to be motivated to achieve high performance and demonstrated enhanced attention during the

13 whole experiment, younger adults might have not put much effort in responding quickly while

14 they could keep accuracy high (Horváth et al., 2009; Iragui et al., 1993; Leiva, Andrés \&

15 Parmentier, 2015).In summary, the present study demonstrated that older adults did not need

16 more time to recover from the sensory effects of distraction than younger adults. This was

17 reflected in the similar modulation of the N1 (presumably mainly the processing negativity) as

18 the glide-gap separation interval shortened which was not influenced by age: from gaps without preceding glides to $150 \mathrm{~ms}$ glide-gap separation both groups showed gradual amplitude attenuation. The modulation of $\mathrm{N} 2$ and P3b indicated that the disruption of attentional trace caused by glides affected later processes as well, like stimulus categorization and target detection.

22 The behavioral results showed that while both groups kept gap detection accuracy high, older adults slowed down as glide-gap separation decreased in contrast to younger adults whose reaction times were not affected. Taken together, our results suggest that although the distracted state does not last longer in the older than in the younger adults, older subjects were nonetheless more affected by distracters in consecutive processing levels as reflected by reaction times. 
1 The present study was supported by the Hungarian Scientific Research Fund - OTKA (104635), 2 the $2015^{\text {th }}$ year fund of Doctoral School of Psychology, Eötvös Loránd University, and the János 3 Bolyai Research Scholarship of the Hungarian Academy of Sciences (János Horváth). 


\section{Figure captions}

2 Fig. 1: The schematic design of the experimental tones reflecting glide-gap separation intervals

3 and epoch types. The different colors represent the different glide-gap separations in the 4 continuous tone.

$5 \quad$ Fig. 2: The gap-related raw ERPs, the corresponding control ERPs and their difference (corrected 6 waveforms) for each glide-gap separations.

7 Fig. 3: Group mean reaction times (left) and gap-detection rates (right; both with standard errors 8 of the means indicated by whiskers) in the younger and older adult group for the four types of 9 gaps (150, 250, $650 \mathrm{~ms}$ glide-gap separation, and gap only trials).

10 Fig. 5: ERP Group-mean normalized gap-related N1 amplitudes (with standard errors of the 11 means indicated by whiskers) for of 150, 250 and $650 \mathrm{~ms}$ glide-gap separations measured at a 12 fronto-central cluster $(\mathrm{FCz}, \mathrm{FC} 1, \mathrm{FC} 2, \mathrm{Fz}$, and $\mathrm{Cz}$ ). The amplitudes were normalized by the 13 corresponding group-mean ERP amplitudes for the corrected gap only trials.

14 Fig. 6: Topographies of the group-mean gap- and the glide-related ERPs in the N1 (top and 15 middle raws, measured at mastoid and at fronto-central peaks) and P2 (bottom) intervals in the 16 younger and older adult groups. The amplitude scales differ between groups in order to 17 adequately represent the shapes of topographies while showing the amplitude differences for each 18 gap type within each group.

19 Fig. 7: Topographies of the group-mean later gap-related components. N2 is presented in top and $20 \mathrm{P} 3 \mathrm{~b}$ is presented in bottom row. The amplitude scales are set to reflect the amplitude differences 21 within each group. 


\section{References}

Alain, C., McDonald, K. L., Ostroff, J. M., \& Schneider, B. (2004). Aging: A Switch From Automatic to Controlled Processing of Sounds? Psychology and Aging, 19(1), 125-133. doi: 10.1037/0882-7974.19.1.125

Alho, K. (1992). Selective Attention in Auditory Processing as Reflected by Event-Related Brain Potentials. Psychophysiology, 29(3), 247-263. doi: 10.1111/j.1469-8986.1992.tb01695.x

Alho, K., Paavilainen, P., Reinikainen, K., Sams, M. \& Näätänen, R. (1986). Separability of Different Negative Components of the Event-Related Potential Associated with Auditory Stimulus. Psychophysiology, 23(6), 613-623. doi: 10.1111/j.1469-8986.1986.tb00680.x

Amenedo, E., \& Díaz, F. (1998). Automatic and effortful processes in auditory memory reflected by event-related potentials. Age-related findings. Electroencephalography and Clinical Neurophysiology/Evoked Potentials Section, 108(4), 361-369. doi: 10.1016/S01685597(98)00007-0

Anderer, P., Semlitsch, H. V., \& Saletu, B. (1996). Multichannel auditory event-related brain potentials: effects of normal aging on the scalp distribution of N1, P2, N2 and P300 latencies and amplitudes. Electroencephalography and Clinical Neurophysiology, 99, 458-472. doi: 0.1016/S0013-4694(96)96518-9

Berti, S., Grunwald, M., \& Schröger, E. (2013). Age dependent changes of distractibility and reorienting of attention revisited: An event-related potential study. Brain Research, 1491, 156-166. doi: http://doi.org/10.1016/j.brainres.2012.11.009

Carlson, M. C., Hasher, L., Conelly, S. L., \& Zacks, R. T. (1995). Aging, distraction, and the benefits of predictable location. Psychology and Aging, 10(3), 427-436. doi: 10.1037/0882-7974.10.3.427

Ceponiene, R., Alku, P., Westerfield, M., Torki, M., \& Townsend, J. (2005). ERPs differentiate syllable and nonphonetic sound processing in children and adults. Psychophysiology, 42(4), 391-406. http://doi.org/10.1111/j.1469-8986.2005.00305.x

Chao, L. L., \& Knight, R. T. (1997). Prefrontal deficits in attention and inhibitory control with aging. Cerebral Cortex, 7(1), 63-69. doi: 10.1093/cercor/7.1.63 
Crowley, K. E., \& Colrain, I. M. (2004). A review of the evidence for P2 being an independent component process: age, sleep and modality. Clinical Neurophysiology, 115(4), 732-744. http://doi.org/10.1016/j.clinph.2003.11.021

Czigler, I., Csibra, G., \& Csontos, A. (1992). Age and inter-stimulus interval effects on eventrelated potentials to frequent and infrequent auditory stimuli. Biological Psychology, 33(2-3), 195-206. doi:10.1016/0301-0511(92)90031-OEscera, C., \& Corral, M.-J. (2003). The distraction potential (DP), an electrophysiological tracer of involuntary attention control and its dysfunction. In I. Reinvang, M. W. Greenlee, \& Herrmann, M. (Eds.), The Cognitive Neuroscience of Individual Differences-New Perspectives (pp. 63-76). Oldenburg, Germany: Bibliotheks-und Informationssystem der Universität Oldenburg.

Falkenstein, M., Yordanova, J., \& Kolev, V. (2006). Effects of aging on slowing of motorresponse generation. International Journal of Psychophysiology, 59(1), 22-29. http://doi.org/10.1016/j.ijpsycho.2005.08.004

Folstein, J. R., \& Van Petten, C. (2008). Influence of cognitive control and mismatch on the N2 component of the ERP: A review. Psychophysiology, 45(1), 152-170. doi: 10.1111/j.14698986.2007.00602.x

Forstmann, B. U., Tittgemeyer, M., Wagenmakers, E.-J., Derrfuss, J., Imperati, D., \& Brown, S. (2011). The Speed-Accuracy Tradeoff in the Elderly Brain: A Structural Model-Based Approach. Journal of Neuroscience, 31(47), 17242-17249. http://doi.org/10.1523/JNEUROSCI.0309-11.2011

Friedman, D. (2012). The components of aging. Oxford Handbook of Event-Related Potential Components, 513-536. doi: 10.1093/oxfordhb/9780195374148.013.0243

Friedman, D., Cycowicz, Y. M., \& Gaeta, H. (2001). The novelty P3: An event-related potential (ERP) sign of the brain's evaluation of novelty. Neuroscience \& Biobehavioral Reviews, 25, 355-373. doi: 10.1016/S0149-7634(01)00019-7

Gaeta, H., Friedman, D., Ritter, W., \& Cheng, J. (1998). An event-related potential study of agerelated changes in sensitivity to stimulus deviance. Neurobiology of Aging, 19(5), 447459. doi: 10.1037/0882-7974.16.1.55 
Getzmann, S., Gajewski, P. D., \& Falkenstein, M. (2013). Does age increase auditory distraction? Electrophysiological correlates of high and low performance in seniors. Neurobiology of Aging, 34(8), 1952-1962. http://doi.org/10.1016/j.neurobiolaging.2013.02.014

Guerreiro, M. J. S., Murphy, D. R., \& Van Gerven, P. W. M. (2010). The role of sensory modality in age-related distraction: A critical review and a renewed view. Psychological Bulletin, 136(6), 975-1022. http://doi.org/10.1037/a0020731

Hansen, J. C., \& Hillyard, S. A. (1980). Endogenous brain potentials associated with selective auditory attention. Electroencephalography and Clinical Neurophysiology, 49, 277-290. doi: 10.1016/0013-4694(80)90222-9

Harris, K. C., Wilson, S., Eckert, M. A., \& Dubno, J. R. (2012). Human Evoked Cortical Activity to Silent Gaps in Noise: Effects of Age, Attention, and Cortical Processing Speed. Ear and Hearing, 33(3), 330-339. http://doi.org/10.1097/AUD.0b013e31823fb585

Hasher, L., Lustig, C., \& Zacks, R. (2007). Inhibitory mechanisms and control of attention. In A. Conway, C. Jarrold, M. Kane, A. Miyake, \& J. Towse (Eds.), Variations in Working Memory. Oxford University Press. doi:10.1093/acprof:oso/9780195168648.003.0009

Hillyard, S. A., Hink, R. F., Schwent, V. L., \& Picton, T. (1973). Electrical signs of selective attention in the human brain. Science, 182(4108), 177-180. doi: 10.1126/science.182.4108.177

Horváth, J. (2014a). Probing the sensory effects of involuntary attention change by ERPs to auditory transients. Psychophysiology, 51(5), 489-497. doi: 10.1111/psyp.12187

Horváth, J. (2014b). Sensory ERP effects in auditory distraction: did we miss the main event? Psychological Research, 78(3), 339-348. http://doi.org/10.1007/s00426-013-0507-7

Horváth, J., \& Burgyán, A. (2011). Distraction and the auditory attentional blink. Attention, Perception and Psychophysics, 73, 695-701. doi: 10.3758/s13414-010-0077-3

Horváth, J., Czigler, I., Birkás, E., Winkler, I., \& Gervai, J. (2009). Age-related differences in distraction and reorientation in an auditory task. Neurobiology of Aging, 30(7), 11571172. doi: http://doi.org/10.1016/j.neurobiolaging.2007.10.003 
Horváth, J., \& Winkler, I. (2010). Distraction in a continuous-stimulation detection task. Biological Psychology, 83(3), 229-238. doi: 10.1016/j.biopsycho.2010.01.004

Horváth, J., Winkler, I., \& Bendixen, A. (2008). Do N1/MMN, P3a, and RON form a strongly coupled chain reflecting the three stages of auditory distraction? Biological Psychology, 79(2), 139-147. doi: 10.1016/j.biopsycho.2008.04.001Iragui, V. I., Kutas, M., Mitchiner, M. R., \& Hillyard, S. A. (1993). Effects of aging on event-related brain potentials and reaction times in an auditory oddball task. Psychophysiology, 30, 10-22. doi: 10.1111/j.1469-8986.1993.tb03200.x

Jemel, B., Oades, R. D., Oknina, L., Achenbach, C., \& Röpcke, B. (2003). Frontal and temporal lobe sources for a marker of controlled auditory attention: the negative difference $(\mathrm{Nd})$ event-related potential. Brain Topography, 15(4), 249-262. doi: 10.1023/A:1023915730566

Kaernbach, C. (1990). A single-interval adjustment-matrix (SIAM) procedure for unbiased adaptive testing. Journal of the Acoustical Society of America, 88(6), 2645-2655. doi: $10.1121 / 1.399985$

Karayanidis, F., Andrews, S., Ward, P. B., \& Michie, P. (1995). ERP indices of auditory selective attention in aging and Parkinson's disease. Psychophysiology, 32, 335-350. doi: 10.1111/j.1469-8986.1995.tb01216.x

Kok, A. (2000). Age-related changes in involuntary and voluntary attention as reflected in components of the event-related potential (ERP). Biological Psychology, 54(1), 107-143. doi: 10.1016/S0301-0511(00)00054-5

Lange, K. (2013). The ups and downs of temporal orienting: a review of auditory temporal orienting studies and a model associating the heterogeneous findings on the auditory N1 with opposite effects of attention and prediction. Frontiers in Human Neuroscience, 7. doi: 10.3389/fnhum.2013.00263

Leiva, A., Andrés, P., \& Parmentier, F. B. R. (2015). When aging does not increase distraction: Evidence from pure auditory and visual oddball tasks. Journal of Experimental Psychology: Human Perception and Performance, 41(6), 1612-1622. doi: 10.1037/xhp0000112 
Leiva, A., Parmentier, F. B. R., \& Andrés, P. (2014). Aging increases distraction by auditory oddballs in visual, but not auditory tasks. Psychological Research, 79(3), 401-410. doi: $10.1007 / \mathrm{s} 00426-014-0573-5$

Lustig, C., Hasher, L., \& Zacks, R. (2007). Inhibitory Deficit Theory: Recent developments in a "new view". In A. Conway, C. Jarrold, M. Kane, A. Miyake, \& J. Towse (Eds.), Variations in Working Memory. Oxford University Press. doi: 10.1037/11587-008

Mager, R., Falkenstein, M., Störmer, R., Brand, S., Müller-Spahn, F., \& Bullinger, A. H. (2005). Auditory distraction in young and middle-aged adults: a behavioural and event-related potential study. Journal of Neural Transmission, 112(9), 1165-1176. doi: 10.1016/j.cub.2013.04.053

Mueller, V., Brehmer, Y., von Oertzen, T., Li, S.-C., \& Lindenberger, U. (2008). Electrophysiological correlates of selective attention: A lifespan comparison. BMC Neuroscience, 9(1), 18. doi: 10.1186/1471-2202-9-18

Näätänen, R. (1982). Processing negativity: An evoked-potential reflection. Psychological Bulletin, 92(3), 605-640. doi: 10.1037/0033-2909.92.3.605

Näätänen, R. \& Michie, P. (1979). Early selective-attention effects on the evoked potential: A critical review and reinterpretation. Biological Psychology, 8, 81-136. doi: 10.1016/03010511(79)90053-X

Näätänen, R., \& Picton, T. (1987). The N1 wave of the human electric and magnetic response to sound: A review and an analysis of the component structure. Psychophysiology, 24(4), 375-425. doi: 10.1111/j.1469-8986.1987.tb00311.x

Näätänen, R., \& Winkler, I. (1999). The concept of auditory stimulus representation in cognitive neuroscience. Psychological Bulletin, 125(6), 826-859. doi: 10.1037/00332909.125.6.826

Nuwer, M., Comi, G., Emerson, R., Fuglsang-Frederiksen, A., Guérit, J. M., Hinrichs, H., Ikeda, A., Luccas, F.J.C., \& Rappelsburger, P. (1998). IFCN standards for digital recording of clinical EEG. Electroencephalography and Clinical Neurophysiology, 106, 259-261. doi: 10.1016/S0013-4694(97)00106-5 
Okamoto, H., Stracke, H., Wolters, C. H., Schmael, F., \& Pantev, C. (2007). Attention Improves Population-Level Frequency Tuning in Human Auditory Cortex. Journal of Neuroscience, 27(39), 10383-10390. doi: 10.1523/JNEUROSCI.2963-07.2007

Patel, S. H., \& Azzam, P. N. (2005). Characterization of N200 and P300: Selected Studies of the Event-Related Potential. International Journal of Medical Sciences, 2(4), 147-154. doi: 10.7150/ijms.2.147

Pfefferbaum, A., Ford, J. M., Roth, W. T., \& Kopell, B. S. (1980). Age-related changes in auditory event-related potentials. Electroencephalography and Clinical Neurophysiology, 49(3-4), 266-276. doi: 10.1016/0013-4694(80)90221-7

Polich, J. (2007). Updating P300: An integrative theory of P3a and P3b. Clinical Neurophysiology, 118(10), 2128-2148. doi:10.1016/j.clinph.2007.04.019

Reuter-Lorenz, P. A., \& Cappell, K. A. (2008). Neurocognitive aging and the compensation hypothesis. Current Directions in Psychological Science, 17(3), 177-182. doi: 10.1111/j.1467-8721.2008.00570.x

Ritter, W., Simson, R., Vaughan, G. H., \& Macht, M. (1982). Manipulation of Event-Related Potential Manifestations of Informational Processing States. Science, 218, 909-911. doi: 10.1126/science. 7134983

Salthouse, T. A. (2000). Aging and measures of processing speed. Biological Psychology, 54(13), 35-54. doi: 10.1016/S0301-0511(00)00052-1

Schröger, E. (1996). A neural mechanism for involuntary attention shifts to changes in auditory stimulation. Journal of Cognitive Neuroscience, 8(6), 527-539. doi: 10.1162/jocn.1996.8.6.527

Shen, D., \& Alain, C. (2010). Neuroelectric correlates of auditory attentional blink. Psychophysiology, 47, 184-191. doi: 10.0000/j.1469-8986.2009.00924.x

Shen, D., \& Mondor, T. A. (2006). Effect of distractor sounds on the auditory attentional blink. Perception \& Psychophysics, 68(2), 228-243. doi: 10.3758/BF03193672

Shepherd, D., Hautus, M., Stocks, M. A., \& Quek, S. Y. (2011). The single interval adjustment matrix (SIAM) yes - no task: an empirical assessment using auditory and gustatory 
stimuli. Attention, Perception and Psychophysics, 73, 1934-1947. doi: 10.3758/s13414011-0137-3

3 Slawinski, E. B., \& Goddard, K. M. (2001). Age-related changes in perception of tones within a stream of auditory stimuli: Auditory Attentional Blink. Canadian Acoustics, 29(1), 3-12.

5 Tomé, D., Barbosa, F., Nowak, K., \& Marques-Teixeira, J. (2015). The development of the N1 6 and N2 components in auditory oddball paradigms: a systematic review with narrative analysis and suggested normative values. Journal of Neural Transmission, 122(3), 375391. doi: 10.1007/s00702-014-1258-3

9 Tremblay, S., Vachon, F., \& Jones, D. M. (2005). Attentional and perceptual sources of the auditory attentional blink. Perception \& Psychophysics, 67(2), 195-208. doi: 10.3758/BF03206484

Woods, D. L. (1992). Auditory selective attention in middle-aged and elderly subjects: an eventrelated potential study. Electroencephalography and clinical Neuropsychology, 84, 456468. doi: 10.1016/0168-5597(92)90033-8

Woods, D. L., \& Clayworth, C. C. (1987). Scalp topographies dissociate N1 and Nd components during auditory selective attention. Current Trends in Event-Related Potential Research (EEG Suppl. 40), 155-160.

Zanto, T. P., \& Gazzaley, A. (2014). Attention and ageing. In A. C. Nobre, \& S. Kastner (Eds.), 19 The Oxford Handbook of Attention (pp. 927-971). Oxford University Press.

20 


\begin{tabular}{|ccccc|}
\hline Group & $\mathbf{2 5 0 ~ H z}$ & $\mathbf{5 0 0 ~} \mathbf{~ H z}$ & $\mathbf{1 0 0 0 ~} \mathbf{~ H z}$ & $\mathbf{2 0 0 0 ~} \mathbf{~ z z}$ \\
\hline Younger & $14.38( \pm 4.16)$ & $8.91( \pm 5.34)$ & $2.81( \pm 4.91)$ & $3.59( \pm 4.62)$ \\
\hline Older & $25.78( \pm 7.94)$ & $23.125( \pm 10.75)$ & $14.69( \pm 10.54)$ & $23.125( \pm 12.94)$ \\
\hline & $\mathrm{t}=7.195, \mathrm{p}<.001$ & $\mathrm{t}=6.695, \mathrm{p}<.001$ & $\mathrm{t}=5.776, \mathrm{p}<.001$ & $\mathrm{t}=8.043, \mathrm{p}<.001$ \\
\hline
\end{tabular}

2

Table 1. Group-mean hearing thresholds $(\mathrm{dB})$ and standard deviations in the 3 younger and older adult groups.

4 


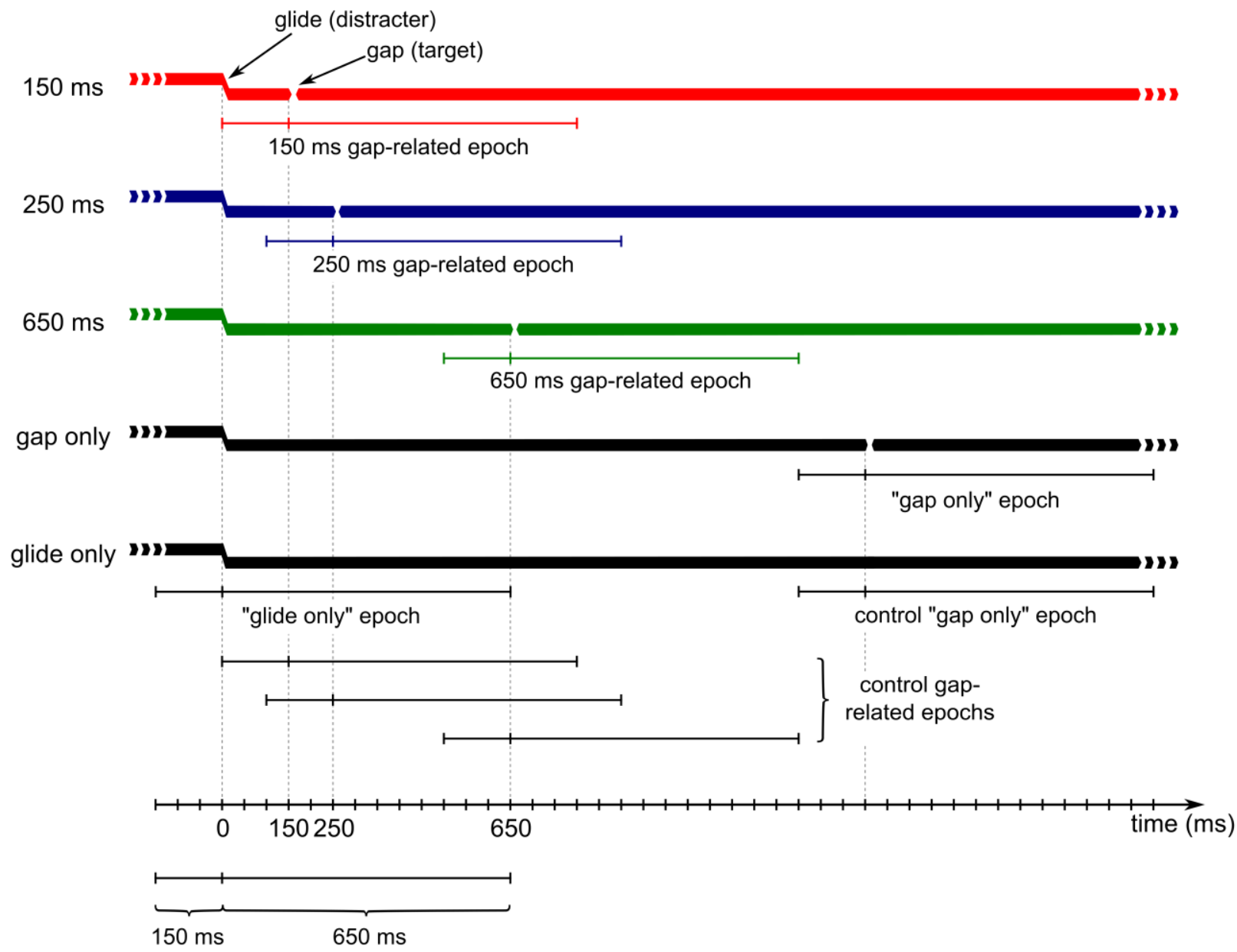

2 Fig. 1: The schematic design of the experimental tones reflecting glide-gap separation intervals 3 and epoch types. The different colors represent the different glide-gap separations in the 4 continuous tone. 


\section{Glide-gap separation}

younger adults $150 \mathrm{~m}$

$250 \mathrm{~ms}$

$\mathrm{FCz}$ cluster
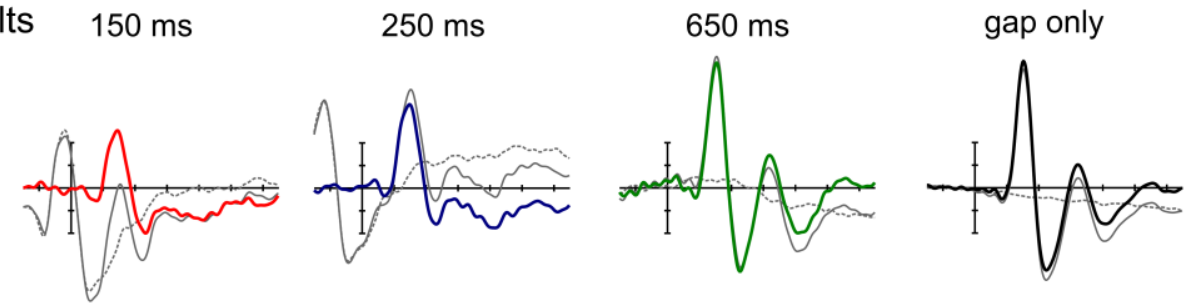

$\mathrm{Pz}$
cluster
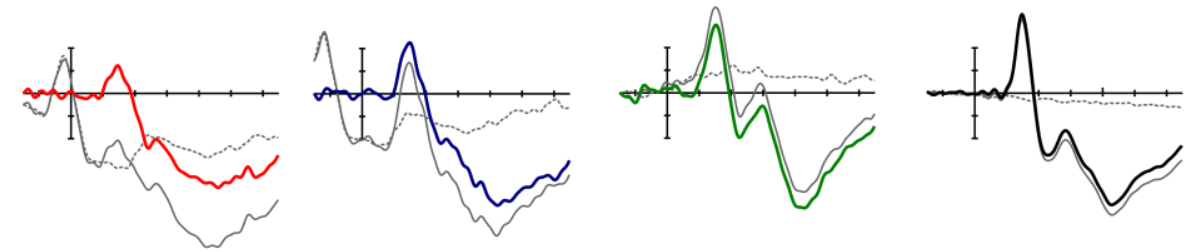

M
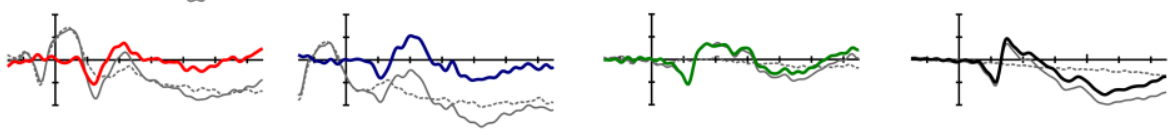

older adults

$650 \mathrm{~ms}$

gap only

$\mathrm{FCz}$ cluster
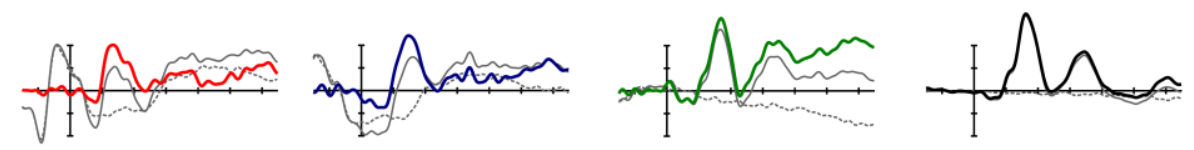

$\mathrm{Pz}$ cluster
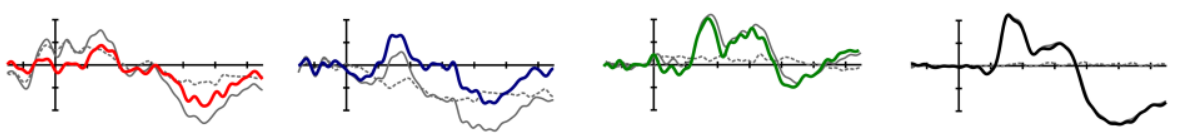

M
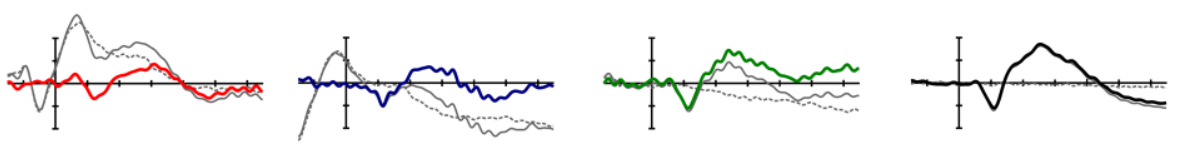

Raw ERPs

group averaged ERP

group averaged control gap

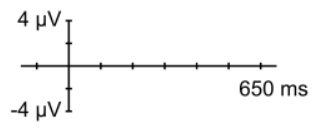

Corrected waveforms

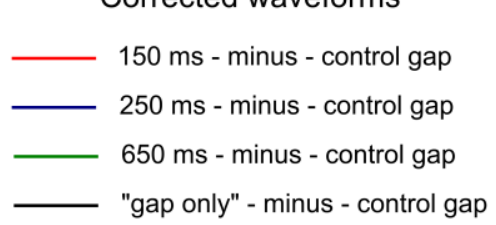

2 Fig. 2: The gap-related raw ERPs, the corresponding control ERPs and their difference (corrected 3 waveforms) for each glide-gap separations. 
Reaction times to gaps

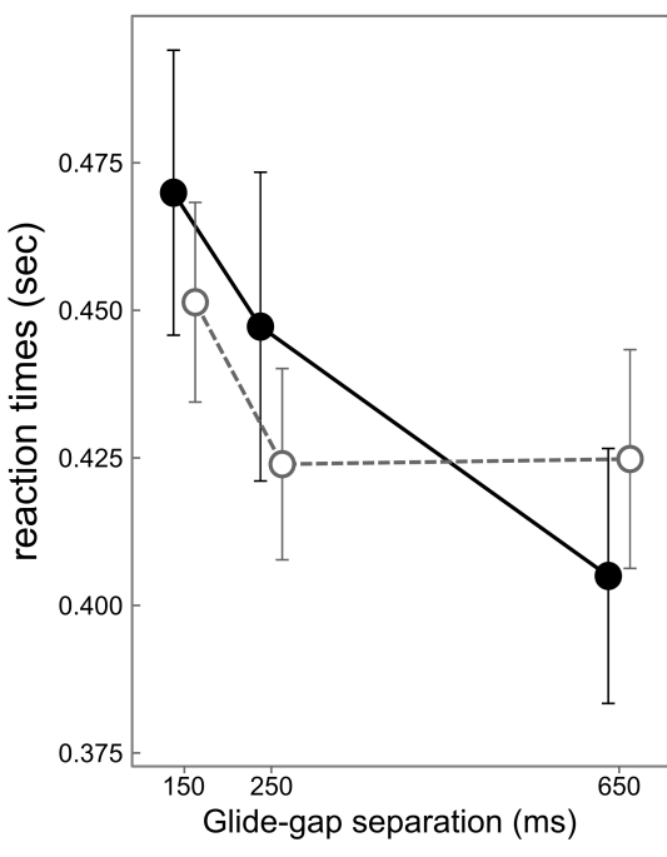

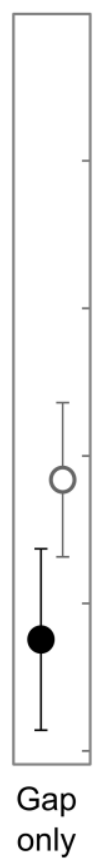

Gap detection rate

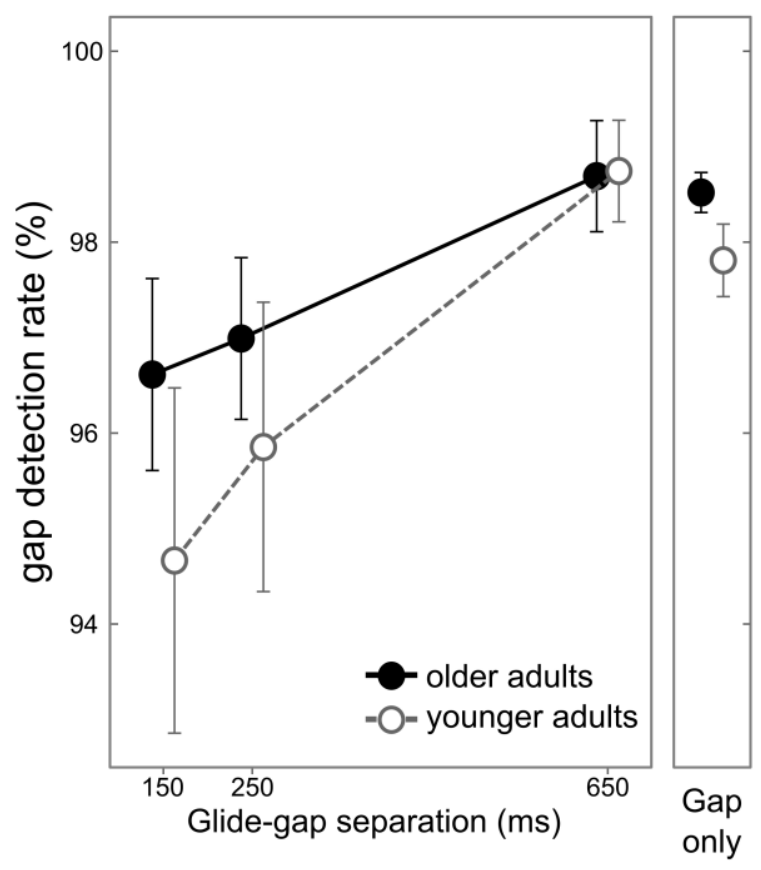

1

3 Fig. 3: Group mean reaction times (left) and gap-detection rates (right; both with standard errors 4 of the means indicated by whiskers) in the younger and older adult group for the four types of 5 gaps (150, 250, $650 \mathrm{~ms}$ glide-gap separation, and gap only trials). 


\section{Gap-related ERPs}

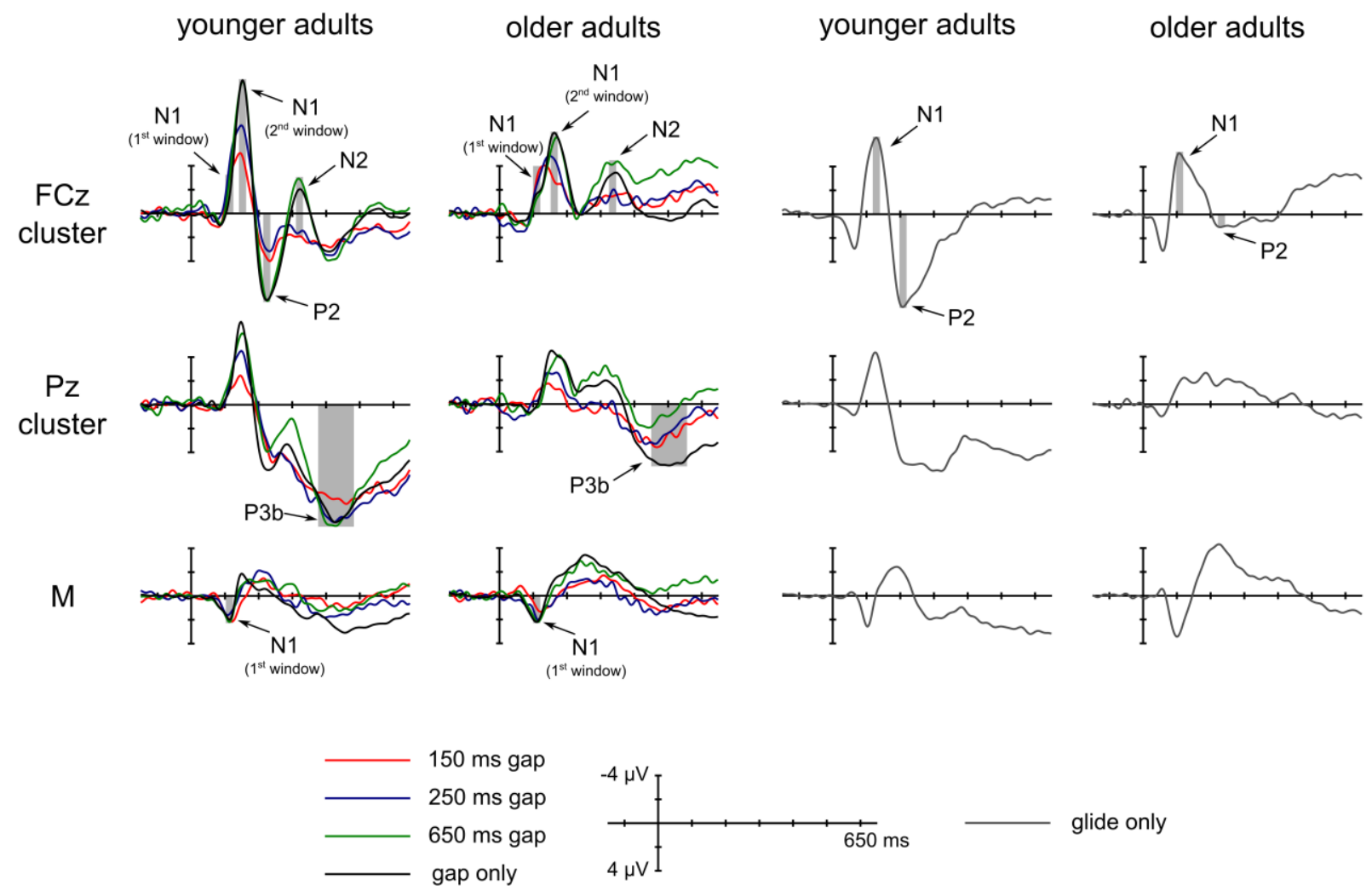

1

4 control glide-related ERPs are shown. The grey bands index the time windows (20 ms for N1, P2 5 and $\mathrm{N} 2$ and $100 \mathrm{~ms}$ for P3b) where statistical analyses were assessed. 


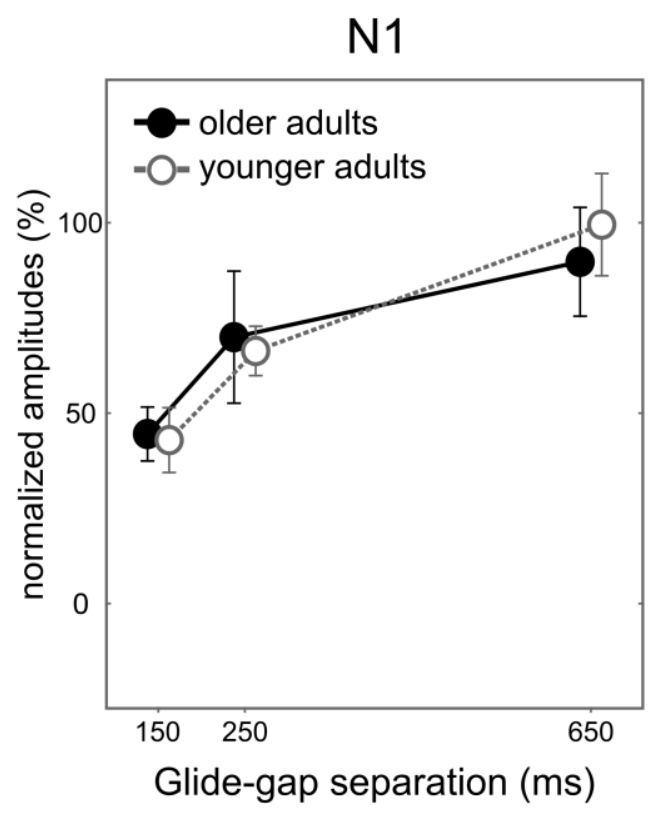

2 Fig. 5: ERP Group-mean normalized gap-related N1 amplitudes (with standard errors of the 3 means indicated by whiskers) for of 150, 250 and $650 \mathrm{~ms}$ glide-gap separations measured at a 4 fronto-central cluster $(\mathrm{FCz}, \mathrm{FC} 1, \mathrm{FC} 2, \mathrm{Fz}$, and $\mathrm{Cz})$. The amplitudes were normalized by the 5 corresponding group-mean ERP amplitudes for the corrected gap only trials. 


\section{Topographical distributions of gap- and glide-related N1 and P2}

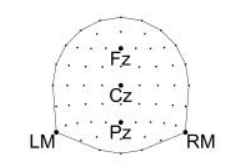
younger adults
(104-124 ms)

older adults (100-120 ms)

$$
\begin{aligned}
& 150 \\
& \mathrm{~ms}
\end{aligned}
$$

$$
250
$$

$\mathrm{ms}$

650

$\mathrm{ms}$

gap

only

N1 - first time window
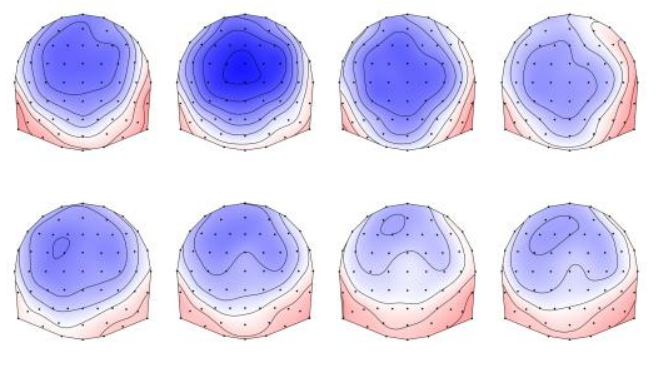

$\mathrm{N} 1$ - second time window

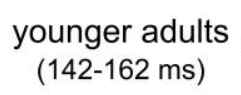

older adults (150-170 ms)
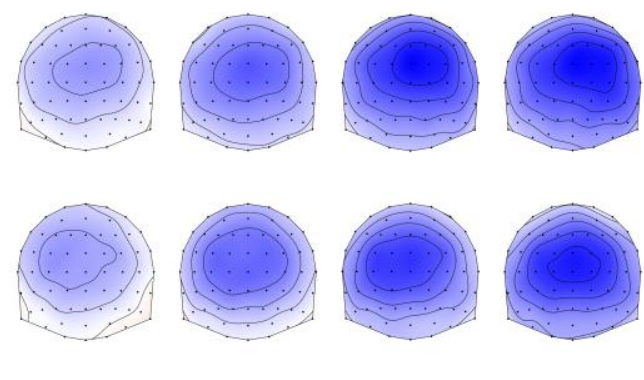

P2

\begin{abstract}
younger adults
\end{abstract} (208-228 ms)
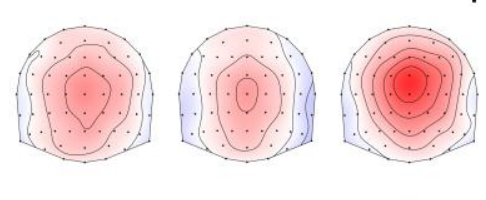

older adults (220-240 ms)
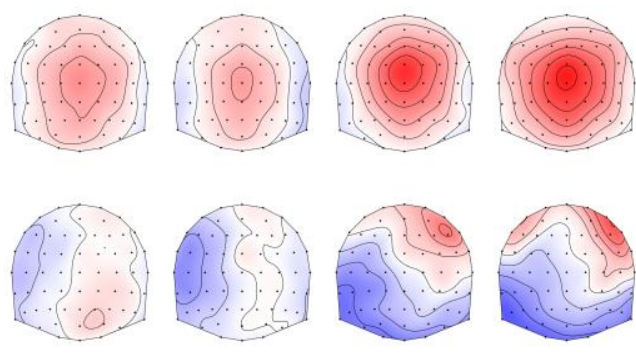

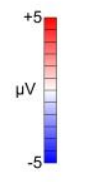

glide

only
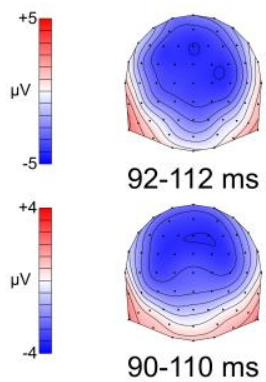

90-110 ms

1

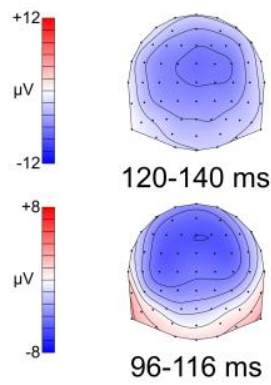

2 Fig. 6: Topographies of the group-mean gap- and the glide-related ERPs in the N1 (top and

3 middle rows, measured at mastoid and at fronto-central peaks) and P2 (bottom) intervals in the

4 younger and older adult groups. The amplitude scales differ between groups in order to

5 adequately represent the shapes of topographies while showing the amplitude differences for each

6 gap type within each group. 


\section{Topographical distributions of gap-related N2 and P3b}

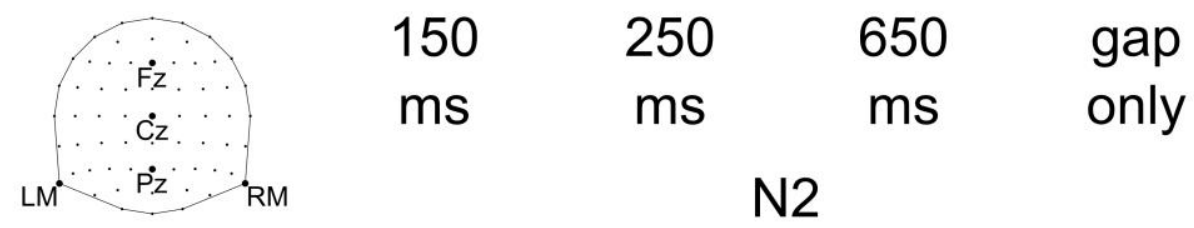

younger adults

(316-336 ms)
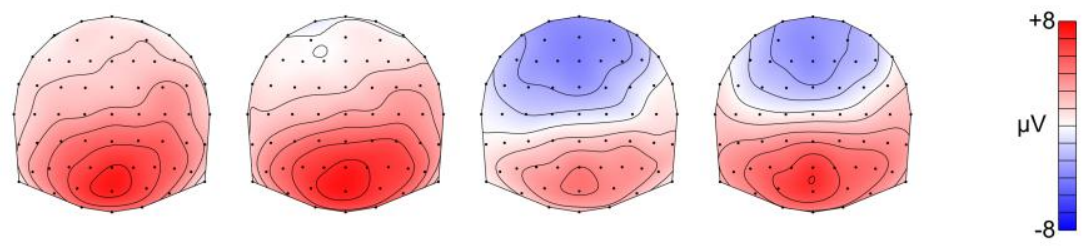

older adults

(318-338 ms)
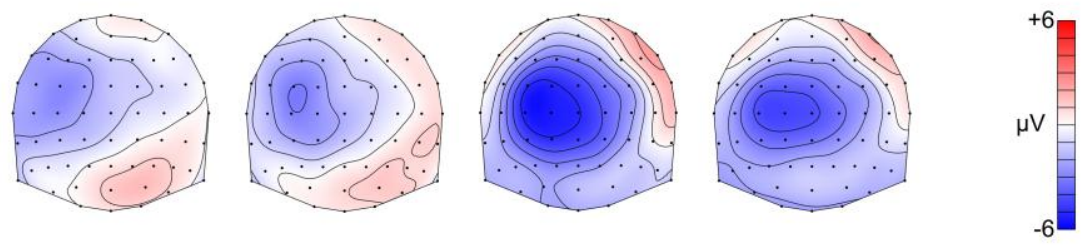

$\mathrm{P} 3 \mathrm{~b}$

younger adults

(378-478 ms)
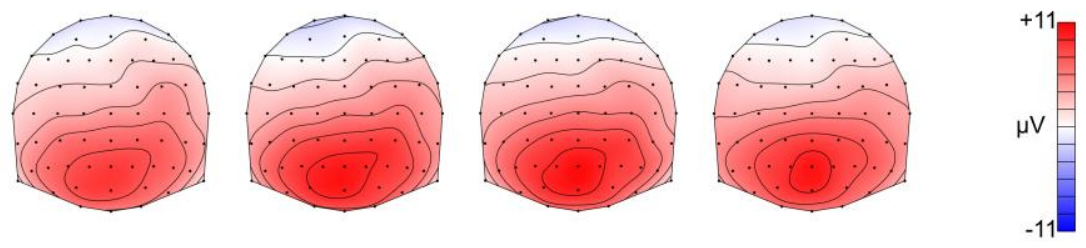

older adults

(452-552 ms)
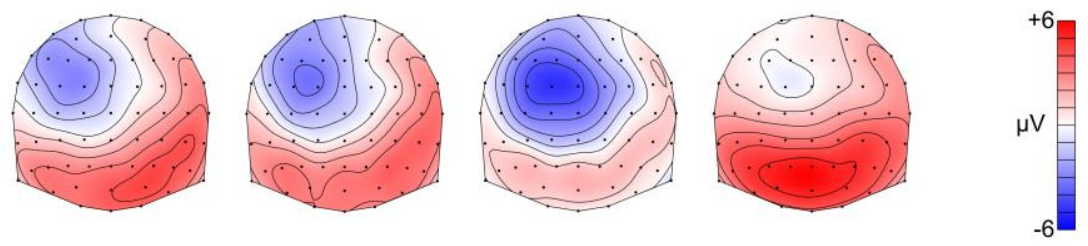

2 Fig. 7: Topographies of the group-mean later gap-related components. N2 is presented in top and

$3 \quad \mathrm{P} 3 \mathrm{~b}$ is presented in bottom row. The amplitude scales are set to reflect the amplitude differences

4 within each group. 